\title{
Complex Formation in Concentrated Sulfuric Acid between Selenium(IV) and 1-Aminoanthraquinone
}

\author{
I NGVAR DAHL and JAN A. MYHRSTAD * \\ Chemical Institute A, University of Oslo, Blindern, Oslo 3, Norway
}

\begin{abstract}
The complex formation in concentrated sulfuric acid between selenium(IV) and 1-aminoanthraquinone (Am) was studied by spectrophotometry, infrared spectroscopy, and chemical analysis. The system was found to contain one species, the dimer $\mathrm{Se}_{2} \mathrm{Am}_{2}$ complex. The complex was prepared in the solid state.
\end{abstract}

Methods for the photometric determination of selenium are mostly based on its colour reactions with various aromatic $o$-diamines or the reduction to elementary selenium. Recent investigations in this laboratory have demonstrated that selenium as selenium(IV) reacts with aromatic compounds containing amino and carbonyl groups, e.g. the dianthrimides. ${ }^{1-5}$ The coloured complexes are formed in concentrated sulfuric acid by heating mixtures of the reactants.

It was considered of interest to study the complex formation between selenium(IV) and other aromatics containing amino and carbonyl groups, and in this paper an investigation of 1-aminoanthraquinone is described. Under the present experimental conditions no complex formation was found to take place between selenium(IV) and 2-aminoanthraquinone.

\section{EXPERIMENTAL}

Instruments and equipment. Extinction measurements were made with a Zeiss spectrophotometer PMQ II, a Beckman DB recording spectrophotometer and 1-cm silica cells.

The solutions were prepared and heated in 50- or 100-ml bottles (Jenaer Geräteglas) with ground-glass stoppers. Where required, the solutions were heated in an ordinary thermostatically controlled drying oven.

Reagents. The 1-aminoanthraquinone was supplied by Fluka A.G., Switzerland. The structure of the reagent was confirmed by infrared spectroscopy. Quantitative elemental analysis gave the following percentages: $\mathrm{C} 75.22 ; \mathrm{H} \mathrm{4.05;} \mathrm{N} \mathrm{6.05}$. (Theoretical percentages for $\mathrm{C}_{14} \mathrm{H}_{9} \mathrm{NO}_{2}$ are given in Table 1.)

\footnotetext{
* Present address: Norwegian Institute for Water Research, Blindern, Oslo 3, Norway.
}

Acta Chem. Scand. 20 (1966) No. $?$ 
The selenium dioxide (Koch-Light Laboratories Ltd., England) contained at least $99.999 \% \mathrm{SeO}_{2}$.

The concentrated sulfuric acid $(95-97 \%)$ and other chemicals were of reagentgrade quality.

Standard solutions. Sulfuric acids of varying strength were prepared by adding distilled water to concentrated acid, the exact strength being determined alkalimetrically.

Standard solutions of selenium(IV) and 1-aminoanthraquinone were prepared by weighing out and dissolving the proper amounts in $91.0 \%$ sulfuric acid and diluting to a known volume with the same solvent. Precautions were taken to protect the solutions of 1-aminoanthraquinone against light.

\section{RESULTS AND DISCUSSION}

Effect of heat treatment and concentration of sulfuric acid. Preliminary investigations showed that mixtures of the reactants had to be heated in order to obtain complex formation. On the basis of these investigations a heating temperature of $160^{\circ}$ and a heating time of $16 \mathrm{~h}$ were chosen.

The effect of the concentration of sulfuric acid was studied on solutions heated for $16 \mathrm{~h}$ at $160^{\circ}$. The results demonstrated that the concentration of acid was not critical in the range about 89 to $92 \%$. In all experiments an acid concentration of $91.0 \%$ was maintained.

Absorption curves. Absorption curves of two solutions, both belonging to the series of solutions prepared in connection with the use of the method of continuous variation (vide infra), were recorded. The solutions represented a mole ratio of selenium(IV) to 1-aminoanthraquinone corresponding to $1: 4$ and 4:1. The blank solutions contained the same amounts of the reagent as the sample solutions.

The two absorption curves, reproduced in Fig. 1, exhibit the same form, this indicating the presence of only one complex. The curves show a predominant maximum at $492 \mathrm{~nm}$ with a distinct shoulder at about $470 \mathrm{~nm}$ and a smaller maximum at $540 \mathrm{~nm}$.

Fig. 1 also shows the absorption curves of the blank solutions as recorded against $91.0 \%$ sulfuric acid. These curves exhibit a broad maximum at about $350 \mathrm{~nm}$.

The method of continuous variation. In the series of solutions prepared the mole fraction $x\left(x=c_{\mathrm{Se}} /\left(c_{\mathrm{Se}}+c_{\mathrm{Am}}\right)\right)$ varied from 0.02 to 0.98 , the constant, total concentration of the reactants was $3.0 \times 10^{-4} \mathrm{M}$. The extinctions were measured at 470, 492, and $540 \mathrm{~nm}$. In Fig. 2 the resulting curves at 492 and $540 \mathrm{~nm}$ are reproduced.

All the curves exhibit a maximum at the mole fraction 0.5. Both curve branches show inversions and approach the origins parabolically. Thus the curves are pointing to the presence of only one complex with a mole ratio of selenium(IV) to 1-aminoanthraquinone (Am) of 1:1. From the theoretical treatment of Klausen and Langmyhr ${ }^{6}$ the conclusion was drawn that the complex was of the form $\mathrm{Se}_{m} \mathrm{Am}_{n}, m=n>1$.

The straight-line method. The straight-line method, as modified by Klausen and Langmyhr, ${ }^{7}$ was used to determine the values of $m$ and $n$ of the complex $\mathrm{Se}_{m} \mathrm{Am}_{n}$. Two series of solutions were prepared, one with a constant concentration of 1-aminoanthraquinone and varying amounts of selenium(IV), and

Acta Chem. Scand. 20 (1966) No. 7 


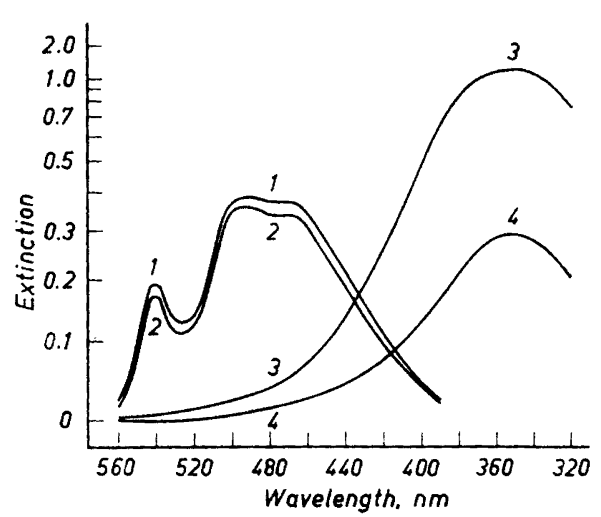

Fig. 1. Absirntion curves of solutions containing the ame total concentration $\left(3.0 \times 10^{-4} \mathrm{M}\right)$, he mole ratio of selenium(IV) to 1 -i:mis:oanthraquinone being 1:4 (curve 1) and 4:1 (curve 2). Absorption curves of the corresponding blanks (curve 3 and curve 4 ), as recorded against $91.0 \%$ sulfuric acid.

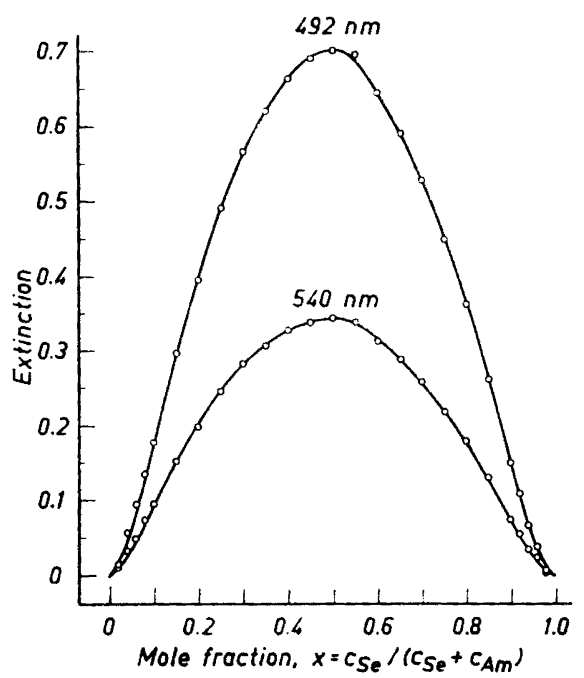

Fig. 2. Curves of continuous variation measured at 492 and $540 \mathrm{~nm}$ for solutions having a total concentration of $3.0 \times 10^{-4} \mathrm{M}$.

another with a constant concentration of selenium(IV) and different amounts of the reagent.

In the first series the concentration of selenium(IV) was varied between $1.5 \times 10^{-5} \mathrm{M}$ and $7.5 \times 10^{-5} \mathrm{M}$, while the constant concentration of 1 aminoanthraquinone was $3.0 \times 10^{-4} \mathrm{M}$. The extinctions were measured at 470,492 , and $540 \mathrm{~nm}$, and in the resulting figure (not reproduced) straight lines were obtained for $m=2$.

In the second series the concentration of 1-aminoanthraquinone was varied from $1.5 \times 10^{-5} \mathrm{M}$ to $7.5 \times 10^{-5} \mathrm{M}$, and the constant concentration of selenium(IV) was $3.0 \times 10^{-4} \mathrm{M}$. Measurements at the same wavelengths employed above gave straight lines for $n=2$.

Preparation of the solid complex. $0.28 \mathrm{~g}$ of 1 -aminoanthraquinone and 1.39 $\mathrm{g}$ of selenium dioxide were dissolved in about $100 \mathrm{ml}$ of $91.0 \%$ sulfuric acid, the mole ratio of selenium(IV) to 1-aminoanthraquinone corresponding to 10:1. After heating for $70 \mathrm{~h}$ at $70^{\circ}$ the solution was cooled to room temperature and then added slowly to a 21 beaker containing a mixture of ice and water, which was stirred vigorously. The violet coloured precipitate was collected on a loose-textured filter and washed with hot and cold water until sulfate and selenite could no longer be detected in the wash water. After drying in contact with air a dark crystalline powder was obtained. 
Investigations of the solid complex

Absorption curves. $0.0250 \mathrm{~g}$ of the preparation were dissolved in $91.0 \%$ sulfuric acid and diluted to $100 \mathrm{ml}$ with the same solvent. To $1 \mathrm{ml}$ of this solution $20 \mathrm{ml}$ of $91.0 \%$ sulfuric acid were added, and an absorption curve was recorded against a blank of $91.0 \%$ sulfuric acid. Further $0.0250 \mathrm{~g}$ of 1 aminoanthraquinone and $0.1243 \mathrm{~g}$ of selenium dioxide (the mole ratio of selenium(IV) to 1-aminoanthraquinone being 10:1) were dissolved in $91.0 \%$ sulfuric acid, diluted to $100 \mathrm{ml}$ with the same solvent and heated for $16 \mathrm{~h}$ at $160^{\circ}$. After cooling to room temperature $1 \mathrm{ml}$ of the solution was mixed with $20 \mathrm{ml}$ of $91.0 \%$ sulfuric acid, and an absorption curve was run as above. In the visual spectral range the two curves were identical in form, but at wavelengths below $340 \mathrm{~nm}$ they were differing, the reason for this probably being a contamination of 1-aminoanthraquinone in the solid complex.

Determination of the molecular weight. Attempts were made to determine the molecular weight of the solid compound by a micro cryoscopic method ( $d$-camphor being used as solvent), but reproducible results were not obtained.

Qualitative and quantitative analysis. Qualitative tests of the compound confirmed the presence of selenium and nitrogen, while the test for sulfur was negative. The results obtained by quantitative elemental analysis are given in Table 1 (average of two independent analyses). In this table also theoretical percentages of 1-aminoanthraquinone $\left(\mathrm{C}_{14} \mathrm{H}_{9} \mathrm{NO}_{2}\right)$, the $\mathrm{Se}_{2} \mathrm{Am}_{2}$ complex $\left(\mathrm{C}_{28} \mathrm{H}_{18} \mathrm{~N}_{2} \mathrm{O}_{8} \mathrm{Se}_{2}\right)$ and of a mixture containing $78.85 \%$ of the complex and $21.15 \%$ of 1 -aminoanthraquinone are listed. (A mixture of this composition may be calculated from the percentage of carbon in the solid compound, found by the elemental analysis).

Table 1. Data relating to the elemental analysis.

\begin{tabular}{|lccccc|}
\hline $\mathrm{C}_{14} \mathrm{H}_{9} \mathrm{NO}_{2}(223.2)$ & & $\mathrm{C}$ & $\mathrm{H}$ & $\mathrm{N}$ & $\mathrm{Se}$ \\
\hline $\mathrm{C}_{28} \mathrm{H}_{18} \mathrm{~N}_{2} \mathrm{O}_{8} \mathrm{Se}_{2}(668.4)$ & Calc. & 75.33 & 4.06 & 6.27 & 0 \\
\hline $78.85 \% \mathrm{C}_{28} \mathrm{H}_{18} \mathrm{~N}_{2} \mathrm{O}_{8} \mathrm{Se}_{2}+21.15 \%$ & Calc. & 50.32 & 2.71 & 4.19 & 23.63 \\
$\mathrm{C}_{14} \mathrm{H}_{9} \mathrm{NO}_{2}$ & & & & & \\
& Calc. & 55.61 & 3.00 & 4.63 & 18.63 \\
\hline
\end{tabular}

Infrared spectroscopy. Infrared spectra (nujol mull) were recorded of 1aminoanthraquinone and the solid complex. As the complex was contaminated by 1-aminoanthraquinone, few definite conclusions could be drawn concerning the bondings in the former compound. However, a frequency shift of the strongest band due to the carbonyl absorption indicated that at least one of the carbonyl groups was engaged in complex formation.

Acta Chem. Scand. 20 (1966) No. 7 


\section{CONCLUSION}

The photometric measurements demonstrated that the present system contained only one species, viz. the $\mathrm{Se}_{2} \mathrm{Am}_{2}$ complex. (In the solid state, however, the existence of a monomer SeAm complex is possible.) The solid compound was not pure but contained about $20 \%$ of 1-aminoanthraquinone, probably due to a partly disruption of the complex when precipitated in ice water.

Of the monoaminoanthraquinones only the 1-isomer was found to react with selenium(IV). Regarding the structure of the complex, infrared spectroscopy indicated the presence of a linkage from carbonyl to selenium, the latter being assumed to participate in the reaction as the $\mathrm{HSeO}_{2}{ }^{+}$ion. ${ }^{8}$ There is reason to believe that also the amino group is involved in the complex formation. Thus, a reaction between selenium(IV) and the monoaminoanthraquinones seems to depend upon the amino group being in ortho position to one of the carbonyl groups. (Investigations on the complex formation between selenium(IV) and some diaminoanthraquinones are in progress.)

1-Aminoanthraquinone may be used for the photometric determination of selenium(IV), the sensitivity of the reaction is about $2.5 \times 10^{-2} \mu \mathrm{g} / \mathrm{cm}^{2}$. However, as apparent from previous studies, ${ }^{3}$ the calibration curve will not be linear, but approach the origin parabolically.

\section{REFERENCES}

1. Langmyhr, F. J. and Omang, S. H. Anal. Chim. Acta 23 (1960) 565.

2. Langmyhr, F. J. and Dahl, I. Anal. Chim. Acta 29 (1963) 377.

3. Dahl, I. and Langmyhr, F. J. Anal. Chim. Acta. 35 (1966) 24.

4. Langmyhr, F. J. and Myhrstad, J. A. Anal. Chim. Acta. 35 (1966) 212.

5. Myhrstad, J. A. and Langmyhr, F. J. To be published.

6. Klausen, K. S. and Langmyhr, F. J. Anal. Chim. Acta 28 (1963) 335.

7. Klausen, K. S. and Langmyhr, F. J. Anal. Chim. Acta 28 (1963) 501.

8. Flowers, R. H., Gillespie, R. J. and Robinson, E. A. J. Inorg. Nucl. Chem. 9 (1959) 155.

Received March 15, 1966. 